\title{
Rational Food Fortification Programs to Alleviate Micronutrient Deficiencies
}

\section{Sunil J Wimalawansa*}

Endocrinology, Metabolism \& Nutrition, Cardio-Metabolic Institute, Somerset, New Jersey, USA

\begin{abstract}
Key presentations of severe malnutrition or undernutrition caused by macronutrient deficiencies are marasmus, a disease causing stunting; wasting; underweight or kwashiorkor; or a combination of these. Micronutrient insufficiencies on the otherhand, cause a variety of disorders, and correction of these deficiencies on an individual basis is cost-prohibitive. Therefore, food fortification is an accepted, practical, and affordable solution to overcome this problem. The cost of adding vitamins and minerals to commonly consumed foods is very low; estimated to range between $0.5 \%$ and $2.0 \%$ of the cost of a typical staple food. For formulations that include vitamin A and D, iron, zinc, and folic acid, the cost is approximately US $\$ 8$ to $\$ 10$ per metric ton. If an individual consumes $100 \mathrm{~g} / \mathrm{day}$ ( $37 \mathrm{~kg} /$ year) of the final product, the cost of fortification is approximately US $\$ 0.40$ per person/year; a cost that is affordable to industry and consumers. For more complex formulations, such as the World Food Program's (WFP) Corn Soy Blend, the cost increases to US $\$ 1.0$ per person per year. The WFP estimates a minimum normal "food basket" cost of approximately US $\$ 0.25$ per person/day or US $\$ 92$ per year. Thus, the cost of adding micronutrients is approximately $0.6 \%$ of the food in the basic food basket or, at the higher end, about $1 \%$ of added cost. Nevertheless, the outcomes of alleviating micronutrient deficiencies, decreasing the disease burden, improve productivity, and the cost-effectiveness is exceptional. Targeted food fortification programs that focused on the poor, communities and developing countries, would be the most cost-effective and beneficial in alleviating micronutrient deficiencies. In addition to enhancing the production of healthy food and assuring its wide availability, and the affordability, the food industry should constantly develop healthful, nutritious foods using innovative technologies and market these products to consumers at affordable prices. Cost-effective and practical micronutrient food-fortification programs should designed to add micronutrients to common staple foods, such as flour or parboiled rice as well as milk and other common used food, depending on the cultural and food habits of individuals in a given country. Food fortification programs must be an integral part of disease prevention and the global health.
\end{abstract}

Keywords: Health; Malnutrition; Vitamins; Minerals; AntiOxidants; Enrichment; Nutrition

\section{Introduction}

Micronutrients, including vitamins, minerals, trace elements, phytochemicals, and antioxidants are essential for good health. In comparison to macronutrients such as carbohydrate, fat and protein, micronutrients are required in much smaller quantities. Nutritional deficiencies are common worldwide. Because of the increasing poverty and global food insecurity, in fact, the incidences of micronutrient deficiencies are continue to increase. Macronutrient and micronutrient deficiency induces disorders that are most common in economically deprived, developing countries. However, underprivileged communities in affluent countries are not immune to these disorders. The term malnutrition includes both undernutrition (stunting and wasting) and over nutrition (obesity).

In general, clinical presentations of macronutrient deficiencies are readily noticeable in patients with severe protein-calorie undernutrition. Nevertheless, they may present differently, depending on whether they suffer from (A) acute or chronic undernutrition, and (B) whether the under nutrition is predominantly due to protein or energy malnutrition. Common presentations of patients with macronutrient undernutrition are illustrated in the Table 1.

Micronutrient malnutrition has many adverse effects on human health, not all of which are clinically evident. Even moderate levels of deficiency (which can be detected only by biochemical measurements or detail clinical examination) can have detrimental effects on physiological functions and in the bodily systems. Thus, in addition to the obvious and direct health effects, the existence of micronutrient malnutrition has profound implications for well-being, economic and social development, and human productivity, particularly in terms of public health costs and loss of productivity caused by human illnesses and absentism.

Depending on what types of food one eats, the quantity and quality of these nutrients and the rate of the intestinal absorption could vary greatly. People with mild to moderate micronutrient deficiency may present with subtle abnormalities. Therefore, it is possible for the health care workers to miss early signs of micronutrient deficiencies and thus, the diagnostic opportunities. Presentations of micronutrient deficiencies can range from mild lethargy, tiredness, skin and visual abnormalities, to serious organ or metabolic failures; the clinical presentation spectrum of these disorders is very large.

Processed foods have more macronutrients and higher concentrations of salt and preservatives than do natural foods, but at the expense of micronutrients. Food processing often removes or decreases micronutrients and the nutritional food value. Levels of minerals,

*Corresponding author: Sunil J Wimalawansa, MD, PhD, MBA, FACE, DSc. Endocrinology, Metabolism \& Nutrition, Cardio-Metabolic Institute, Somerset, New Jersey, USA, E-mail: suniljw@hotmail.com

Received July 31, 2013; Accepted August 24, 2013; Published August 30, 2013

Citation: Sunil J Wimalawansa (2013) Rational Food Fortification Programs to Alleviate Micronutrient Deficiencies. J Food Process Technol 4: 257. doi:10.4172/2157-7110.1000257

Copyright: (C) 2013 Sunil J Wimalawansa. This is an open-access article distributed under the terms of the Creative Commons Attribution License, which permits unrestricted use, distribution, and reproduction in any medium, provided the original author and source are credited. 


\begin{tabular}{|l|l|}
\hline Category & Common presentations of undernutrition \\
\hline A. & Marasmus, a disease characterized by stunting (severe calorie malnutrition) \\
\hline B. & Wasting \\
\hline C. & $\begin{array}{l}\text { Underweight (severe protein malnutrition); loss of muscle is masked by fluid } \\
\text { retention }\end{array}$ \\
\hline D. & Combinations of stunting and wasting \\
\hline
\end{tabular}

Cause

Insufficient height gain relative to age, long-term malnutrition, and poor health Insufficient weight gain relative to height, recent history of losing weight/acute malnutrition

Insufficient weight gain relative to age or losing weight; and kwashiorkor Insufficient weight gain due to protein-calorie undernutrition

Table 1: Common presentations of severer macro-nutrient (protein-energy) undernutrition.

vitamins, and phytochemicals decrease during the processing of food; but processing increases the shelf life of food, taste, and make it easier to transport and store. Consequently, processed food; bread, cereal grains, chips, sweets, pastries, certain dairy products, and most of the fast foods provide concentrated calories but decreased micronutrients.

Fortification of food with micronutrients is different from supplementations given as tablets or capsules. Fortification is the practice of deliberately adding one or more essential micronutrients (i.e., vitamins, minerals, and trace elements) to a particular food to improve the nutritional quality of that food. Fortification should provide public health benefits with minimal or no risks to human health. The term enrichment is used to describe a process that is somewhat similar to fortification but refers to the addition of micronutrients to a food irrespective of whether the nutrients were originally present in the food or not. The aim of both of these processes is to increase the intake of these micronutrients to correct or prevent deficiencies and to provide health benefits. Therefore, food fortification programs work synergistically with the overall nutrition improvement programs to prevent nutrient deficiencies.

\section{Prevalence of micronutrient deficiency}

Although advances in science and medicine continue exponentially, basic health services, particularly nutrition, fail to reach the majority of the global population. It has been estimated that micronutrient deficiencies account for about $7.3 \%$ of the global burden of disease, with iron and vitamin A deficiency ranking among the 15 leading causes of the global disease burden [1]. Recent reports indicate that more than a third of the population in developing countries are undernourished, as indicated by Body Mass Index (BMI) of less than 18.5, whereas another third have acquired an unhealthful accumulation of excess visceral fat (i.e., abdominal obesity); both of these extremes increase morbidity and mortality [2].

Malnutrition is common in socially and economically deprived societies, in certain tribes and castes, and in a large section of minority communities [3-5]. Those who live in wealthier countries have higher incomes, greater access, and ability to purchase a wider variety of micronutrient-rich, fortified foods, which decrease the risk and the prevalence of micronutrient deficiency. Moreover, the micronutrient deficiencies negatively affect the fetal and infant growth, and the well-being, cognitive development, and the resistance to infections in children. Micronutrient deficiencies are widespread. Over $90 \%$ of the severe micronutrient deficiencies affect the poor, food insecure, and vulnerable people in developing countries.

Worldwide, the four most common forms of micronutrient malnutrition are iron, vitamin $\mathrm{A}$, vitamin $\mathrm{D}$ and iodine deficiencies. Together, these affect approximately half of the world's population; the majority of whom live in developing countries. Iron deficiency has multiple causes and probably the most prevalent micronutrient deficiency in the world. The World Health Organization (WHO) reports that more than 2 billion people are anemic, just under 2 billion have inadequate iodine nutrition, and approximately 250 million preschool children are vitamin A deficient (Figure 1).

\section{Why nutritional deficiencies are escalating globally?}

Many in the undernourished groups live a day-to-day existence, and some rely fully on homegrown or locally produced food. Thus, they have less variety of food to rely upon. Fortification is often the more cost-effective and practical way to provide micronutrients to communities or countries in need, especially if the technology already exists and if an appropriate and equitable food distribution system is in place [6-8]. It is usually possible to add multiple micronutrients without substantially increasing the total cost of the food product at the point of manufacture.

However, despite good intentions, fortified foods often fail to reach the poorest segments of the population; those who are at the greatest risk of micronutrient deficiency. In part, this is because such groups have difficulty in accessing fortified foods and their low purchasing power. In addition, distribution channels to poorer populations are weak or in some areas, non-existing. The availability, access, consumption of adequate quantities micronutrient-rich foods such as animal products, fruits, and vegetables are limited and expensive, and availability and the costs are highly variable in globally.

Unfortunately, only a relatively small portion of resources in the world is allocated for solving health problems of developing countries. Lower the economic capability of a given society or a country, lesser the amount it would spent on healthful food, distribution channels and research. Consequently, there is a major under-investment in health sector research particularly in nutrition that are relevant to the needs of low-income countries. It has been estimated that approximately only $10 \%$ of the world's total health and research expenditure is dedicated to the problems that are affecting $80 \%$ of the world's population [9]. Therefore, the probability of solving important health and nutritional problems in the economically deprived countries are little.

Moreover, most of the allocated funds are earmarked for highprofile or glamorous diseases, thus it further neglect macro- and micronutrition programs. Provision of life saving foods to desperately poor and vulnerable, in situation like famine and floods are critical to save lives, but not a long-term solution. In fact, funds should be allocated and spend to make these communities develop their own sustainable ways of achieving food security and become self-sufficient in food. In addition, the structural and social determinants are also affecting human health. These include availability of basic human needs, such as shelter/housing, clean water and safe sanitation, quality education; and the gender, social and racial equality. These fundamental human needs should be brought to stand equitable, sustainable, and meaningful ways, with tangible developments in a given society or a country.

When one suffer from a dietary deficiency of any nutrient, it is more than likely that he or she is likely to suffer other nutrient 


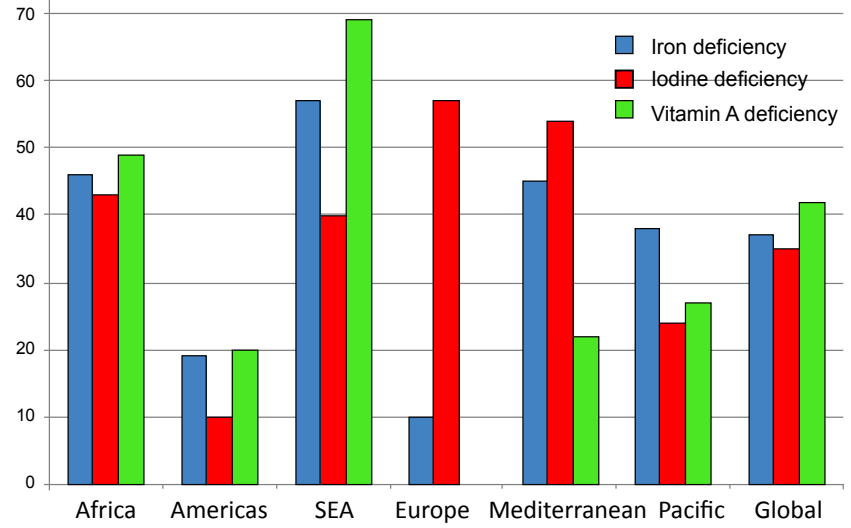

Prevalence of the iron, iodine and vitamin A (three major micronutrient) deficiencies across the continents, in $\mathrm{WHO}$ regions; presented as percentage of population (data adapted from the Table 1.1 of WHO report [10]). Y-axis illustrates the percentage data WHO regions: (Blue bars) Anemia, based on the proportion of the population with hemoglobin concentrations below established cutoff levels [106]; (Red bars) lodine deficiency based on the proportion of the population with urinary iodine $<100 \mu \mathrm{g} / \mathrm{L}$ [35]; (Green bars) Estimated vitamin A deficiency based on the proportion of the population with clinical eye signs and/or serum retinol $\leq 0.70 \mu \mathrm{mol} / \mathrm{L}$ [107]. SEA = Southeast Asian.

Figure 1: Global prevalence of micronutrient deficiency.

deficiencies. Moreover, one micronutrient deficiency can progress to cause other deficiencies. Guidelines provide information about the benefits, limitations, design, implementation, monitoring, regulation, and evaluation of food-fortification programs and their cost-benefit ratios, particularly for developing countries [10]. Each country needs to develop its own food-data system with particular attention given to locally available, natural, and nutritious foods. Rather than using expensive supplements or importing food, it is logical to use a nutritious, locally produced food-based approach in the prevention of macro and the micronutrient deficiencies.

Poverty, lack of access to nutritious food varieties, lack of knowledge of appropriate dietary values and practices, and high incidence of communicable diseases are major factors leading to continuation of micronutrient deficiency. Micronutrient malnutrition and poor socioeconomic status contribute to a negative vicious cycle of health. These situations have long-ranging effects on health, learning ability, productivity and the absenteeism, and high social and public costs associated with reduced work capacity caused by high rates of illness and disability.

\section{Micronutrients and human health}

Vitamins and trace minerals are essential constituents of the human diet. Some vitamins such as vitamin $\mathrm{D}$ can be synthesized in the body but often in inadequate quantities. Only small quantities of these substances are needed for the essential biochemical reactions, including coenzymes and prosthetic groups in enzymatic reactions. Multiple or single nutrient deficiencies are rare but may occur in people who have gastro-enteropathies, are chronically ill or fed parenterally, or consume excessive amounts of alcohol. Abnormalities of micronutrient-related laboratory tests are particularly common in the elderly and among the sick people. Laboratory assays can detect subclinical vitamin and trace mineral deficiencies. While these subclinical deficiencies can cause biochemical and enzymatic abnormalities, the clinical significance of such is not known.
Due to the high variability in composition, consumption, as well as different types of food availability and the heterogeneity in dietetic habits of people, it is difficult to study the effects and health benefits of an individual micronutrient in healthy populations. Therefore, it is not surprising that varied or neutral results that have been reported in studies using micronutrients such as selenium, vitamins $\mathrm{C}$ and $\mathrm{E}$, and folic acid $[11,12]$. As with any food, supplemental vitamins need to be consumed in the right amounts; sometimes less is better ("Let thy food be thy medicine and thy medicine thy food."- Hippocrates). In fact, the majority of people, especially in the west, who routinely consume vitamins and mineral supplements, do not need them. Conversely, those who need them, do not take supplements, because either they have no access or cannot afford to purchase these, or due to lack of awareness. Fast food, frequent travel, busy schedules, little time to cook and eat at home, and the inability to eat together as a family, make it harder to consume a balanced, healthful diet. Consequently, people who can afford them often rely on supplements. Thus, food supplements are a huge growing market in western countries, particularly in the United States (Figure 2).

Economically disadvantaged people (i.e., food insecure groups) mainly rely on energy-dense carbohydrate diets. They have a higher incidence of single or multiple micronutrient deficiencies and many also suffer from central obesity [13]. Moreover, high levels of phytates and polyphenols in rice- and wheat-based diets decrease the intestinal absorption of some vitamins and minerals [14]. These components bind to some micronutrients in the food, forming insoluble complexes, which prevent their absorption. Attempts have been made to enhance intestinal micronutrient absorption by the addition of chemical enhancers such as $\mathrm{Na}_{2}$ EDTA to food [15-18]. However, the long-term safety of these pharmacologic and perhaps unphysiological approaches has not been established.

It is possible that adding chemicals to the diet will cause an imbalance of nutrient ratios and absorption variabilities leading to unintended consequences, including one or more nutrient deficiencies or even precipitation of a disease status. Although it seems efficacious, the addition of synthetic chemicals and preservatives to food also raises concerns about potential long-term safety and aggravation of chronic diseases $[19,20]$. Such diseases include bone loss, osteoporosis and factures; Alzheimer's disease, allergies, chronic kidney and liver diseases, digestive track diseases, heart diseases, and cancer. On the

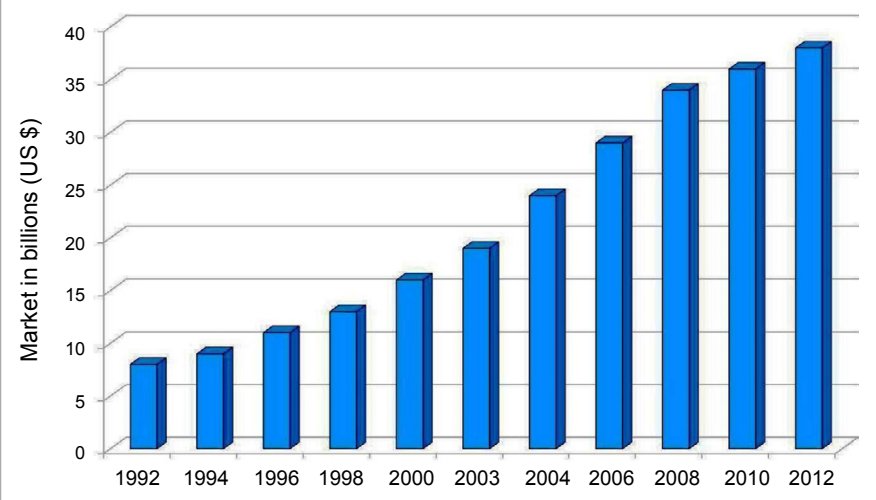

The longitudinal growth of the dietary supplement market in the United States (data summarized from multiple sources)

Figure 2: Micronutrients and food supplement markets in United States of America. 
other hand, some food-fortification programs, such as enriching parboiled rice, milk, sugar, and flour, with micronutrients and vitamins, are not only practical, but also cost-effective, safe, and thus, worth scaling-up for distribution to the needy communities.

\section{Examples of fortification to combat specific micronutrient deficiencies}

Food-based fortification has been accomplished with wheat and maize flour, cereal-based foods, bread, dairy products, rice, soy and fish-source-based fortifications, salt (iodine), oil, butter, and margarine (for fat soluble vitamins). Examples of the desired outcome with such programs include averting clinical and subclinical vitamin A deficiency, anemia, goiter, iodine deficiency, and vitamin D deficiency. However, the benefits of correcting micronutrient deficiency must be weighed against the potential safety issues. Nevertheless, in the vast majority of situations, benefits far outweigh the minor potential risks of fortification. Following are a few examples of micronutrient deficiencies and different approaches that have been taken to overcome these.

Iodine deficiency: Iodine is an essential micronutrient for the synthesis of thyroid hormones [21]. In addition to the over hypothyroidism and goiter formation, it was recognized in early 1980's that the iodine deficiency and consequent hypothyroidism was one of the most common cause of preventable brain damage and mental impairments in childhood [22,23]. In addition to defective brain development, iodine deficiency during pregnancy increases the risk of stillbirth and $\backslash$ incidence of low-birth-weight infants [24,25]. Thyroid hormones are critical for the cerebro-neural development of fetuses and infants; so iodine deficiency during pregnancy can cause irreversible harm to infants [26]. The American Association of Clinical Endocrinologists recommends that women who are currently pregnant, planning to become pregnant, or lactating to consume 150 $\mu \mathrm{g}$ of iodine daily.

The well-tested technology of salt iodization is a practice adapted worldwide to prevent iodine deficiency in humans. In the early 1920 s salt iodization was introduced in the United States of America $[27,28]$ and in Switzerland [29]. Over the years, most countries in the world have incorporated this valuable enrichment technology. In addition to the iodination of salt, the use of prenatal multivitamins containing iodine is the most cost-effective option to supplement iodine to pregnant mothers in developing countries [30,31]. Potassium iodide is the preferred iodine supplement [30,32].

Salt iodization is a highly cost-effective fortification program that eliminates iodine deficiency and iodine-deficiency goiters. Consequently, most governments have incorporated this procedure into their national health and food programs. The usefulness and the efficiency of these programs has been reported in many countries. For example, a randomized, double-blind study conducted in Moroccan schoolchildren demonstrated that fortification of salt with iron and iodine improved both iron and iodine statuses [33]. In Michigan, United States, iodization of salt reduced the goiter rates from about $40 \%$ to less than $10 \%[28,34]$. Despite such convincing evidence in support of salt iodization, it was estimated that approximately 50 countries still have inadequate iodine nutrition, as estimated by median urinary iodine of less than $100 \mu \mathrm{g} / \mathrm{L}$ [35].

Vitamin A deficiency: Vitamin A status is an important determinant of survival of children. Adequate vitamin A promotes and maintains healthy epithelia and thus prevents infections, diarrhea, and eye disorders, including keratomalacia, Bitot's spots, and night blindness. Correction of childhood vitamin A deficiency lowers the risk of morbidity and mortality from communicable viral diseases, such as measles, as well as all-cause mortality [36-38]. Therefore, in developing countries where food fortification programs are less than adequate, and the food insecurity is high, it would be wise and cost-effective to take the measures to control vitamin A (and other common micronutrient) deficiency via food fortification.

Iron deficiency: Iron deficiency anemia exacerbates the negative outcomes of protein-calorie malnutrition. Severe anemia also increases the incidence of maternal and childhood mortality [39]. Supplementation with iron not only corrects iron-deficient anemia, but also improves general well-being, physical and mental activities, cognitive function, school performance, and work efficiency [40,41]. The provision of iron-fortified food to children substantially reduces iron-deficiency anemia.

Adding micronized ferric pyrophosphate at a two-fold higher level $(0.5 \mu \mathrm{m})$ to rice has been recommended. Iron fortification of infant formulas caused a significant decrease in the prevalence of anemia in preschool children in the United States [42,43]. In 1993 Venezuela started a broader food fortification program with wheat and maize flours using a mixture of ferrous fumarate and elemental iron, vitamin $\mathrm{A}$, and a number of $\mathrm{B}$ vitamins. This introduction of iron fortification of flour led to a significant reduction in iron deficiency among children in Venezuela [44]. Similarly, fortification of milk with iron and ascorbic acid in Chile led to a rapid reduction of iron deficiency in infants and in younger children $[45,46]$.

Vitamin D deficiency: Vitamin D deficiency is the most underdiagnosed and perhaps the most common medical condition in the world [47]. It is estimated that more than 2 billion people worldwide, across all ethnic and age groups have vitamin $\mathrm{D}$ deficiency or insufficiency [48-50]. This is one of the few deficiencies that span, worldwide equally affecting the poor and the economically well-to do countries [47, 51]. Studies conducted in multiple European countries reported marked variations in vitamin D statuses [52-54]. Common factors leading to high prevalence of vitamin $\mathrm{D}$ include sun-avoidance, less exposure to sunlight, low dietary intake of vitamin D-rich foods, limited or no access to fortification of food with vitamin $\mathrm{D}$, and differences and variability of biochemical assays measuring serum vitamin D levels [55-57].

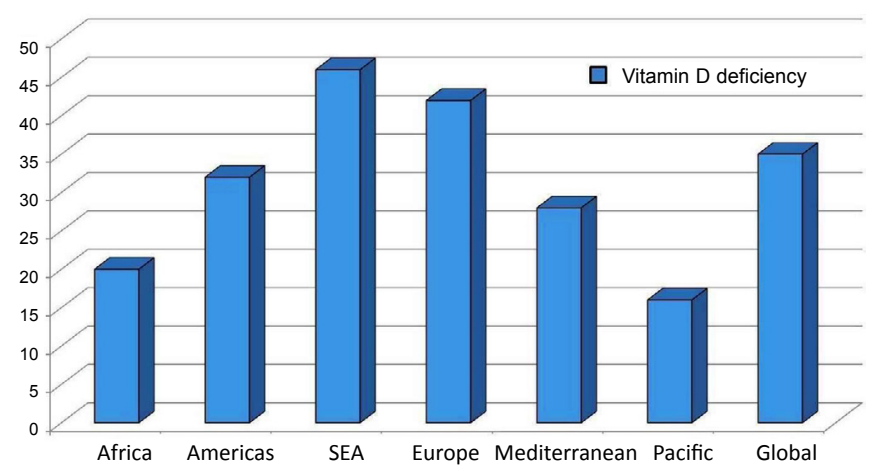

$\mathrm{Y}$-axis (\%): Estimated prevalence (percentage) of vitamin D deficiency [serum $25(\mathrm{OH})$ vitamin $D$ levels less than $30 \mathrm{ng} / \mathrm{mL}(75 \mathrm{pmol} / \mathrm{L})]$ in WHO regions (X-axis) as percentage of population. Average data are summarized from multiple sources. SEA: Southeast Asia.

Figure 3: The global prevalences of vitamin D deficiency illustrated World Health Organization (WHO) regions. 
Vitamin D plays an important role in the proper functioning of virtually all tissues, including muscles, the nervous system, immune system, blood clotting, and skeletal homeostasis [58,59]. More than half of the world's population lacks adequate exposure to sunshine and thus cannot maintain physiological levels of serum $25(\mathrm{OH})$ vitamin D [25(OH)D] [50,54]. However, vitamin D can also acquired through diet (but only in small quantities) and affordable supplements. Although some foods, such as milk and orange juice, are fortified with vitamin $\mathrm{D}$, studies have shown that approximately two-billion people in the world still consume insufficient amounts of this nutrient and, thus are vitamin D insufficient [60-63]. Figure 3 illustrates the estimated worldwide prevalence of vitamin D deficiency.

The understanding of the role of vitamin $\mathrm{D}$ in overall health and awareness of its deficiency is increasing [64-66]. However, translation of this knowledge into clinical practice is lagging, as suggested by the declining average serum $25(\mathrm{OH}) \mathrm{D}$ levels seen during the past 25 years in the United States $[67,68]$. This is likely attributable to a number of reasons including sun-avoidance behavior, the epidemic of obesity and type 2 diabetes, and changing dietetic patterns including lower consumption of dairy products and milk. The consumption of large quantities of processed food that contain preservatives, and nutrientbinders, the relative overuse of sunscreens, and clothing choices in certain populations are some additional risk factors contributing to this silent epidemic of vitamin D deficiency [51].

People with dark skin have lower circulatory $25(\mathrm{OH}) \mathrm{D}$ levels than those with lighter skin $[47,58]$. This is due to the combination of less consumption of dietary vitamin D and supplements (i.e., food habits), and less dermal synthesis of vitamin D secondary to high melanin content in the skin that blocks UVB rays [56,57,69-72] and sunavoidance. Lower serum 25(OH)D levels and lower vitamin D intakes have been reported in African-American and Hispanic populations $[62,68]$. In the 2004 National Health and Nutrition Examination Survey (NHANES) in the United States, data from 6,275 randomly selected children showed a prevalence of $9 \%$ of vitamin D deficiency [i.e., serum $25(\mathrm{OH}) \mathrm{D}$ levels $<15 \mathrm{ng} / \mathrm{mL}$ ] and $61 \%$ with vitamin $\mathrm{D}$ insufficiency (levels between 16 and $30 \mathrm{ng} / \mathrm{mL}$ ).

The virtual elimination of childhood rickets in industrialized countries is attributable to vitamin D fortification of milk, which was first introduced in the United States in the mid-1930s and later adapted by Canada [52]. Nevertheless, there are some signs that rickets is re-emerging as a public health problem even in these two countries, especially among minorities and immigrant populations [51,73]. Among African American women, a low intake of milk is a predictor of a higher prevalence of vitamin D deficiency [74].

Vitamin D fortification of milk also reduces the risk of osteomalacia and osteoporosis in the elderly, especially in higher altitude regions where levels of incident ultraviolet light are lower during the winter months [75,76]. Fortification generally aims to supply micronutrients in amounts that approximate those provided by a good, well-balanced diet and/or to achieve physiologically optimal blood levels [i.e., serum 25(OH) vitamin D levels between 30 and $50 \mathrm{ng} / \mathrm{mL}][58,59]$. Consequently, fortified staple foods thought to contain "natural" or near-natural levels of micronutrients, which may not necessarily be the case with supplements.

Zinc deficiency: Intervention trials have demonstrated that zinc supplementation improves the growth of stunted children with zinc deficiency [77], and improves wound healing. Zinc supplementation also lowered the rates of infectious diarrhea and pneumonia; two leading causes of childhood deaths [78,79]. There are other examples of micronutrients, such as selenium and fluoride (for the prevention of dental caries), used as supplements or in fortification.

\section{Economic Aspects and Practical Approaches to Overcome Micronutrient Deficiencies}

Food fortification can take several forms. It is possible to fortify foods that are widely consumed by the general population (mass fortification), or target population subgroups (focused fortification). Example of targeted fortification includes, complementary foods for preschool or younger children or for displaced populations. Mass fortification is generally the best option when the majority of the population has an unacceptably low levels of a specific micronutrient, and are at a high public health risk. Fortifications are also undertaken voluntarily by food manufacturers to fortify foods in the marketplace; a market-driven fortification. Sometimes this is done to replenish the lost micronutrients during food processing, but other times to overcome competition and/or increase the marketability.

Because of the widespread prevalence of nutrient deficiencies in certain ethnic groups even in economically advanced countries, the clinical identification and correction of these deficiencies on an individual basis is cost-prohibitive. However, the provision of micronutrients through general food fortification programs is a practical and affordable way to solve such problems. The cost of adding calculated amounts of vitamins and minerals to commonly consumed foods is very low. The cost of the ingredients for fortification is estimated to range between $0.5 \%$ and $2.0 \%$ of the cost of a typical staple food. Using more expensive formulation that includes vitamin A, iron, zinc and folic acid, the cost is approximately between US $\$ 8$ to 10 per metric ton. If one assumes that an individual consumes $100 \mathrm{~g} /$ day ( $37 \mathrm{~kg} /$ year) of the final product, the cost of fortification is less than US $\$ 0.50$ per person/year; a cost that is affordable to industries and the consumers.

The extra cost of enrichment programs depends on the range and the type of vitamins and minerals added. However, for complex formulations, such as the World Food Program's (WFP) Corn Soy Blend (CSB Plus), the cost increases to approximately US $\$ 1$ to 2 per person/year, in part because of the more expensive components, such as vitamin $\mathrm{K}$. The WFP calculates a minimum normal "food basket" cost of approximately US $\$ 0.25$ per person/day or US $\$ 92$ per year. Thus, the cost of adding micronutrients is less than $0.5 \%$ of the food in the basic food basket, or at the higher end, an approximately $1 \%$ additional cost. Nevertheless, the outcomes for alleviating micronutrient deficiencies are exceptional, especially for the poor, living in developing countries.

For the Malawi school feeding program by the WFP, the average cost was US $\$ 22$ per child/year; the program provided $100 \mathrm{~g} /$ day of the CSB Plus with all vitamins and minerals, and $11.5 \mathrm{~kg} / \mathrm{month}$ of maize provided for the girls [80]. In addition, to enhance the production of healthy food and assure its availability and affordability, the food industry should constantly develop healthful, nutritious food using innovative technologies and market the products to consumers at affordable prices. Cost-effective and practical micronutrient foodfortification programs should be designed to add micronutrients to staple foods, such as flour or parboiled rice, in individual developing countries. This approach will widen the availability of micronutrients virtually to all, and increase the value of the food and the fortification program. 


\section{Responsibilities of the food industry}

Fortification of food with micronutrients is a valid technology for food-based approach to overcome nutritional deficiency, especially when existing food supplies fail to provide adequate levels of the deficient nutrient. The Codex Alimentarius Commission is an intergovernmental body with over 180 members established by the Food and Agriculture Organization of the United Nations (FAO) and the World Health Organization (WHO) [81]. Fortification is defined by this Commission as the addition of one or more essential nutrients to a food for preventing or correcting a nutritional deficiency in a given population $[82,83]$.

Most industrialized countries have successful food-fortification programs to combat deficiencies of vitamins A and D; B vitamins such as thiamine, riboflavin, and niacin, iodine, and iron [84,85]. Efforts should be made to provide education with reference to micronutrients and encourage appropriate intakes of vitamins, phytochemicals, antioxidants, and other micronutrient components. These are most commonly available in fruits and vegetables; thus, regular intake of these would alleviate micro-nutrient deficiencies and to achieve a healthful balanced diet. Special emphasis should be given to locally available foods that are culturally acceptable and affordable to the local communities. Moreover, it is necessary to identify optimal methods for cooking foods in order to preserve nutrient values and enhance the bioavailability of micronutrients. Modifying the current methods of food preservations without the addition of chemical preservatives and salt are worth exploring.

The gap between the rich and poor within societies and between nations are continues to widen. Similarly, inequities within countries, between urban and rural, men and women, and different ethnic groups are also widening (e.g., poverty, unsafe living and working conditions, racial and gender discrimination, and so forth) [86,87]. The reluctance by the food industry to embrace food-fortification programs is understandable, given the additional work such as changing labels, the fear of the unknown, or the perceived insufficient market demand for the newly fortified foods. Food-fortification programs have capital costs attached to them, mostly associated with the installation of new equipment, apparatus maintenance, training staff, legal issues/costs, new packaging, labeling, and quality control costs. The costs associated with the actual micronutrients are however, minimal. In addition to the provision of general fortification information, CODEX STAN 1-1985 provides labeling for prepackaged foods and CODEX STAN 206-1999 provide the labeling guidance for dairy items [81].

\section{Other regulatory and successful approaches in overcoming micronutrient deficiencies}

Worldwide, most of the food fortifications programs are conducted on a volunteer basis. Objectives of the food fortification are, (A) costeffectively maintain or improve the overall nutritional quality of foods, (B) to minimize nutrient imbalance in the food supply by avoiding over or under fortification of food, (C) to eliminate misleading practices or industry advertisements that may mislead or harm the population, (D) to provide specific guidelines to food manufacturers who engaged in food fortification, and (E) to provide balance nutrients in diets for the benefit of the public.

Fortification of food with micronutrients via a food-based approach is a valid and proven technology for reducing micronutrient malnutrition. On the micro level, for a given community, it is necessary to identify, (A) the best locally available food combinations,
(B) appropriate serving sizes that are necessary for preventing micronutrient deficiencies, and (C) methods to promote these locallyavailable food combinations at the community level. On the macro level, one need to discourage the use of toxic pesticides, weedicides, and artificial chemical fertilizers that contaminate the water resources, the environment and the food-chain, while propagating natural, environmentally-friendly agricultural methods that enhance the yields, repealing pests, and enhance the biologic value of micronutrientrich foods. That would further facilitate overcoming micro- and the macronutrient deficiencies and people's understanding of food, and allow them to make the right food choices. Moreover, use of environmentally-friendly agricultural methods would also decrease the chemicals and toxins-associated non-communicable chronic diseases, including chronic kidney and liver diseases, cancer, and brain disorders.

It is important to develop environmentally friendly, sustainable agricultural, horticultural, and animal husbandry methods. This would not only improve the environment and water, but also improve human health. These should be complementary to support and implement a country-specific guidelines, and agricultural and sustainable water use policies. Such coordinated approach will not only save money, but also encourage food-based approaches to further improve and overcome micronutrient deficiencies, and prevent diseases. However, one should take care during the introduction of new fortification programs, assuring prevention of the possibility of overdose, considering consumer choices, and cultural and social acceptance. There are also other issues and concerns to consider when introducing a food-based micronutrient enrichment program. However, unless marketed at an affordable prices, economically deprived families may not have access to enriched food or may not be able to purchase these value-added foods. If so, there will be a little impact on eliminating micronutrient deficiencies.

Fortification of margarine with vitamin A was first introduced in Denmark to overcome night-blindness, and vitamin $\mathrm{D}$ fortification in milk was introduced in the United States to eliminate rickets. Since the 1940s, the fortification of cereal products with thiamine, riboflavin, and niacin has become a common practice. Folic acid fortification of wheat has become widespread in the United States, Canada, and several other countries, especially to enhance maternal and infant health and to eliminate neural tube defects during gestation.

In recent years, however, fortification has become an increasingly attractive option for overcoming micronutrient deficiencies in the less industrialized countries. There are examples of a number of successful food-fortification programs worldwide, such as fortifying sugar with vitamin A in Central America. Following this fortification, the prevalence of vitamin A deficiency was reduced considerably. Application of these modalities in culturally accepted and nutritionally applicable forms should be considered in other countries. Several countries in sub-Saharan Africa have also adopted fortification of cane sugar, but sugar itself has negative effects on human health. However, there are other countries that would also benefit from such foodfortification programs, based on locally available and affordable food [88].

Biofortification is to breed crops to increase their inherent nutritional values, usually through conventional selective breeding or through via genetic engineering. It differs from food fortification and enrichment, as it focuses on making plants to produce nutrient-rich foods, instead of nutrients added to the foods when they are being processed. It is another technique that has been explored as a means 
of enriching micronutrients in staple foods. Genetic modification of plants and animals to improve the nutrient content and/or absorption is an approach that has been explored widely. Genetic modifications and plant breeding, including enrichment with vitamins, antioxidants and flavinoids in fruits and vegetables, as well as increasing micronutrient content of legumes, tubers, and grains are continuing. Genetic enrichment of a variety of other vegetables and fruits are also being explored [89-91]. Although more research is needed to improve efficiency, concerns have been raised by various groups about the potential safety of genetically modified food, cost to the consumer, and the impact on the environment; these concerns need to be investigated and overcome with proper scientific approaches [92]. Other novel options for food fortification are discussed below.

\section{Food sources as delivery methods to alleviate micronutrient deficiency}

Food fortification is one of the most popular and effective nutritional interventions for improving the dietary nutrients in humans. If made affordable, fortified nutritious food can reach a greater proportion of the population at-risk than any other market interventions, and promote overall health [83]. A number of novel methods have been explored to evaluate the effectiveness of micronutrient fortification and delivery of micronutrients in foods and beverage, in various clinical settings. For example, wheat flour fortified with vitamin $\mathrm{A}$ and provided as buns to Filipino schoolchildren over a 30 -week period, halve the number of children with vitamin A deficiency [93]

A number of trials have evaluated the efficacy of specially formulated foods and beverages as the medium for multiple micronutrient fortification. For example, in South Africa the fortification of biscuits with micronutrients, iron, $\beta$-carotene, and iodine improved the status of these three nutrients in schoolchildren [94]. Tanzanian schoolchildren who were fed with fortified and flavored beverages with 10 different micronutrients led to increased serum retinol levels and reduced iron deficiency status, and the growth rates of children improved [95]. Similarly, in Botswana, school-aged children provided with a beverage enriched with 12 micronutrients experienced increased weight gain and improved iron, folate, riboflavin, and zinc levels [96].

The introduction of fortification of wheat flour with folic acid in the United States in 1998 was accompanied by a significant reduction in the prevalence of neural tube defects [97] and decreased plasma level of homocysteine. A high level of the latter is a risk factor for cardiovascular disease $[98,99]$. In the mid-1940s, the introduction of mandatory fortification programs for certain micronutrients in the United States and in many European countries led to the virtual eradication of some of these deficiencies [100].

\section{Guidance in micronutrient fortification of milk and milk products}

Vitamin D: Vitamin A and D fortification of milk products is subjected to local regulations. In most countries in Asia, South America, and Middle East, vitamin A and D fortificants are allowed in milk powder, but it is a voluntary process. Whole milk fortification in the United States is also voluntary, but approximately $85 \%$ of whole milk in the market is fortified. The currently recommended minimum fortification is $400 \mathrm{IU} /$ quart $(946 \mathrm{~mL})$, which is equivalent to $42.3 \mathrm{IU} / 100 \mathrm{~mL}$, for whole milk and whole powdered milk. The recommended extra allowance is $50 \%$; therefore, up to $600 \mathrm{IU} /$ quart, equivalent to $63.4 \mathrm{IU} / 100 \mathrm{~mL}$ in milk can be fortified. In spite of these, based on a serving size of one cup $(236 \mathrm{~mL})$ per day, these levels are expected to provide only $15 \%$ of the current Daily-Recommended Value (DRV) of $800 \mathrm{IU} /$ day.

Because vitamin D is fat soluble, low-fat powdered milk is "required" to be fortified. However, the current recommendation for vitamin D fortification is the same as for whole milk; therefore, fortification of fat-free milk and milk powders can be safely doubled. In fact, with the new DRV of 800 IU/day, the vitamin D fortification of milk should be doubled. The suggested fortification level is $800 \mathrm{IU} /$ quart (80-85 IU/100 mL), with appropriate allowance for overage. This should provide approximately $25 \%$ of the new DRV for consumption levels of approximately $250 \mathrm{~mL} /$ day. At this level, there would not be any possibility of vitamin over-dosage at consumption of less than $5.0 \mathrm{~L} /$ day, as indicated in the Institute of Medicine (IOM) report and the Endocrine Society guidelines, which indicate safe upper limits of vitamin $\mathrm{D}$ is $4,000 \mathrm{IU}$ per day $[101,102]$.

Vitamin A: Fortification with vitamin A at the level of 2,000 IU/ quart (equivalent to $211 \mathrm{IU} / 100 \mathrm{~mL}$, as reconstituted) is mandatory for low-fat powdered milk in the United States but not for the whole-milk preparations. According to the UNICEF data, as many as one third of Southeast Asian schoolchildren are vitamin A deficient. Therefore, it is logical for these countries to fortify milk products with both vitamin $\mathrm{D}$ and $\mathrm{A}$, at $50 \%$ to $100 \%$ higher than the recommended levels in the United States.

\section{Public-private partnerships to overcome nutritional deficiencies}

Many countries have developed successful partnerships in the health care sector. These mechanisms are much relevant to economically poor countries [103]. Since the resources are limited, synergistic ways of utilizing material and human resources are essential. Public-private partnerships are one example. This can be achieved in areas in which both the public and private sector fall short when operating on their own. These partnerships should reflect the recognition by the public sector, the private sector, and communities at large. Moreover, the emerging health issues and outbreaks require complex executive mechanisms, varied skills, and prompt mobilization of resources and implementation of programs. Both for-profit and not-for-profit private sector establishments should collaborate with the public sector/government in various health sector areas including nutrition, particularly at the community-level.

Moreover, public-private partnerships offer innovative mechanisms for delivering health services including appropriate macro- and micronutrients at an affordable (or even subsidized) prices to the poorer communities [104]. Nevertheless, addressing complex issues and managing diverse partners requires skills and novel ways that call for mutual understanding and flexibility, including organizational and cooperative working cultures of the public and private sectors.

From a disease prevention point of view, balanced nutrition, vaccines, potable water and sanitation are the four most highly effective ways to prevent disease and increase the longevity. These are the most important healthful aspects for eradicating most commonly occurring diseases plaguing the globe. Nevertheless, micronutrient deficiency is also an important aspect that contributes to ill health in humans. To overcome such deficiencies, countrywide and continent-wide complementary nutritional strategies should be considered, including coordinated international cross-border cooperation, integration of services, and agencies dedicated to health and well-being, and effective private-public partnerships. Overall, the cooperative and synergistic 
public-private partnership is the right and cost-effective way to address these issues.

\section{Discussion}

In the European Union, fortified processed foods are a substantial source of micronutrients such as iron and vitamins A and D [105-108]. Close to three billion people in the world today have micronutrient deficiencies caused mostly by a dietary deficiency, parasitic or chronic disease burdens [10]. The best physiological way to prevent micronutrient malnutrition is to ensure consumption of a balanced diet that is adequate in all required nutrients. However, for multiple reasons, this is becoming difficult for many people, so micronutrient deficiencies are becoming commoner worldwide. Therefore, countrywide or communitywide, nutritional education and food fortification programs are needed to overcome these widespread micronutrient deficiencies.

The level of food fortification is resolute as one that achieves sufficiency in the majority of recipients (i.e., more than 95\%) while avoiding potential adverse effects. Cost-effectiveness is defined as the cost of achieving a specified outcome. However, food fortification alone cannot correct micronutrient deficiencies across a country because people living in poverty may not be able to afford, or depending on the geographic localities have little or no access to fortified food or supplements. Moreover, if the degree of micronutrient deficiency is severe or in the existence of high prevalence of chronic diseases including high parasitic infestation loads that increase metabolic demand for micronutrients, additional interventions are necessary.

The goal of fortification of food is to minimize or prevent the risk of micronutrient deficiency in a population. However, constraints including safety or technological issues, and economic considerations can prevent or slow the food-based fortification interventions. At time, mandatory fortification is necessary, when a country faces a widespread and serious public health issue that should cost-effectively overcome by food fortification. The success of a fortification programs are measured through affordability, and its public health impact and its sustainability.

There is considerable experience in the conditions under which food fortification could be recommended as a strategic option for controlling micronutrient malnutrition and overcoming specific health issues. Moreover, the limitations of such fortification and enrichment programs are well known. An understanding of the rationale for such programs, and using and disseminating the right information would improve overall population health outcomes [109]. On the other hand, forced privatization of profitable state assets or natural resources and other detrimental policies that may forced by international lenders, negative effects of globalization, or economic liberalization, and the food industry may further aggravate food insecurity and thus, increase the incidences of macronutrient and micronutrient deficiencies. At the other extreme, controlling wealth and resources via political, civil, or military means for the benefit of the elite would also threaten the democracy, welfare, and the nutrition of a nation's inhabitants.

The best way to prevent micronutrient malnutrition is to ensure consumption of a balanced diet that is adequate in every nutrient. Meanwhile, the public health impact of food fortification depends on a number of parameters but predominantly the level of fortification, the bioavailability of the fortificants, the amount of fortified food consumed, and the cost. However, the more widely and regularly a fortified food is consumed, the greater the likelihood of the prices coming down and the proportion of the population likely to benefit from food fortification.

Market-driven fortification can also improve micronutrient deficiencies, such as certain minerals (e.g., iron and calcium) and selected vitamins (e.g., vitamins C and B2) that are otherwise difficult to add in sufficient amounts through the mass fortification of staple foods and condiments because of safety, technological, or cost constraints. In contrast to most developing countries, where fortifications are predominantly to overcome public health issues. In industrialized countries, market-driven fortification is fairly common due to commercial reasons. However, because of mass media and urbanization, these boundaries are rapidly changing. In spite of these wide-ranging approaches, market-driven fortification programs could clearly play a positive role in alleviating public health issues by focusing on meeting the nutrient requirements, otherwise would not have been accomplished, and thereby reducing micronutrient deficiencies.

Although micronutrient malnutrition is more common and severe in the economically less advanced countries and among the disadvantaged populations, it also represents a public health problem in certain sectors in the affluent and industrialized countries. Nevertheless, causes of micronutrient deficiencies significantly vary among different countries and societies, so the understanding of causes of micronutrient deficiency in a given society is important, prior to implementing a plan to overcome it.

Underlying cause for micronutrient deficiencies vary from economic reasons, such as food affordability, food transportation, processing and cooking issues, or due to cultural or eating habits. Understanding of such is necessary for the stakeholders to design costeffective solutions. The government and the department of health/ nutrition in a given country need to make nutrition and public health a priority through right policies, followed up with the allocation of appropriate resource. In addition, scaling up of sustainable resources, making nutritious food available and affordable through public-private partnerships, educating and encouraging healthful lifestyles and the importance of balance diet and good nutrition, and encouraging people to increase their physical activities would facilitate overcoming micronutrient deficiencies and keeping the nations healthy.

\section{Conflict of Interest}

The author does not have any conflicts of interest.

\section{References}

1. WHO (2002) Reducing Risks, Promoting Healthy Life: Overview. In: The World Health Report, WHO: Geneva, World Health Organization.

2. Wimalawansa SJ (2013) Visceral adiposity and cardiometabolic risks: epidemic of abdominal obesity in North America. Research and Reports in Endocrine Disorders 3: 17-30.

3. Sen B, Bose K, Shaikh S, Mahalanabis D (2010) Prediction equations for bodyfat percentage in Indian infants and young children using skinfold thickness and mid-arm circumference. J Health Popul Nutr 28: 221-229.

4. Sen B, Mahalanabis D, Shaikh S, Kurpad AV, Bose K (2009) Evaluation of equations for fat-free mass based on anthropometry in infants and young children in South Asia. Br J Nutr 101: 551-557.

5. Herath KB, Wimalawansa SJ, Wikramanayake TW, Piyasena RD (1982) Estimation of total body water and water turnover rate in Sri Lankans using tritiated water. Ceylon Med J 27: 20-24.

6. Bank W (1994) Enriching Lives: Overcoming Vitamin and Mineral Malnutrition in Developing Countries. World Bank, Washington DC, USA.

7. Kumar S (1999) Nutrition status of children and women in West Bengalchallenges and opportunities. Indian J Public Health 43: 17-20, 25. 
Citation: Sunil J Wimalawansa (2013) Rational Food Fortification Programs to Alleviate Micronutrient Deficiencies. J Food Process Technol 4: 257. doi:10.4172/2157-7110.1000257

Page 9 of 11

8. Hardy G (1999) Problems and opportunities for nutrition support practitioners Curr Opin Clin Nutr Metab Care 2: 259-260.

9. GlobalForumHealth.org (2007) The 10/90 Gap Now.

10. WHO, FAO (2006) Guidelines on food fortification with micronutrients, Lindsay A, de Benoist B, Omar D, Hurrell R(eds). WHO Publications, USA.

11. Byers T (2010) Anticancer vitamins du Jour-The ABCED's so far. Am J Epidemiol 172: 1-3

12. Clarke R, Halsey J, Lewington S, Lonn E, Armitage J, et al. (2010) Effects of lowering homocysteine levels with $\mathrm{B}$ vitamins on cardiovascular disease cancer, and cause-specific mortality: Meta-analysis of 8 randomized trials involving 37485 individuals. Arch Intern Med 170: 1622-1631.

13. Wimalawansa SJ (2013) Thermogenesis-based interventions for obesity and Type 2 diabetes mellitus. Expert Reviews of Endocrinology \& Metabolism 8: 275-288.

14. Hallberg L, Rossander L, Skånberg AB (1987) Phytates and the inhibitory effect of bran on iron absorption in man. Am J Clin Nutr 45: 988-996.

15. MacPhail AP, Patel RC, Bothwell TH, Lamparelli RD (1994) EDTA and the absorption of iron from food. Am J Clin Nutr 59: 644-648.

16. Davidsson L, Walczyk T, Zavaleta N, Hurrell R (2001) Improving iron absorption from a Peruvian school breakfast meal by adding ascorbic acid or Na2EDTA. Am J Clin Nutr 73: 283-287.

17. Hettiarachchi M, Hilmers DC, Liyanage C, Abrams SA (2004) Na2EDTA enhances the absorption of iron and zinc from fortified rice flour in Sri Lankan children. J Nutr 134: 3031-3036.

18. Hurrell RF, Reddy MB, Burri J, Cook JD (2000) An evaluation of EDTA compounds for iron fortification of cereal-based foods. Br J Nutr 84: 903-910.

19. Ebrahim F, Kimiagar M, Valaei N, Abbasi S (2003) Effect of fortified flour with ferrous sulfate alone and with $\mathrm{Na}_{2}$ EDTA on iron deficiency anemia and serum zinc. Food Agric Environ 1: 69-71

20. Davidsson L, Kastenmayer P, Hurrell RF (1994) Sodium iron EDTA [NaFe(III) EDTA] as a food fortificant: the effect on the absorption and retention of zinc and calcium in women. Am J Clin Nutr 60: 231-237.

21. Zimmermann MB (2009) lodine deficiency. Endocr Rev 30: 376-408.

22. Hetzel BS (1994) The conquest of iodine deficiency disorders. S.O.S. for a Billion. Oxford: Oxford University Press.

23. Hetzel BS (1983) lodine deficiency disorders (IDD) and their eradication. Lancet 2: 1126-1129.

24. Cobra C, Muhilal, Rusmil K, Rustama D, Djatnika, et al. (1997) Infant survival is improved by oral iodine supplementation. J Nutr 127: 574-578.

25. Thilly C, Lagasse R, Roger G, Bourdoux P, Ermans AM (1980) Impaired Fetal and Postnatal Development and High Perinatal Death Rate in a Severe lodine Deficient Area. In: Thyroid Research VIII, Stockigt JR, Nagataki S (eds). Australian Academy of Science, Australia.

26. de Escobar GM, Obregón MJ, del Rey FE (2007) lodine deficiency and brain development in the first half of pregnancy. Public Health Nutr 10: 1554-1570.

27. Kimball OP, Marine D (1992) The prevention of simple goiter in man. Second paper. 1918. Nutrition 8: 200-204

28. Marine D, Kimball OP (1990) The prevention of simple goiter in man. A survey of the incidence and types of thyroid enlargements in the schoolgirls of Akron (Ohio), from the 5th to the 12th grades, inclusive-the plan of prevention proposed 1917. J Lab Clin Med 115: 128-136.

29. Bürgi H, Supersaxo Z, Selz B (1990) lodine deficiency diseases in Switzerland one hundred years after Theodor Kocher's survey: a historical review with some new goitre prevalence data. Acta Endocrinol (Copenh) 123: 577-590.

30. Caldwell KL, Pan Y, Mortensen ME, Makhmudov A, Merrill L, et al. (2013) lodine Status in Pregnant Women in the National Children's Study and in U.S. Women (15-44 Years), National Health and Nutrition Examination Survey 2005-2010. Thyroid 23: 927-937.

31. Sullivan KM, Perrine CG, Pearce EN, Caldwell KL (2013) Monitoring the iodine status of pregnant women in the United States. Thyroid 23: 520-521.

32. Leung AM, Pearce EN, Braverman LE (2009) lodine content of prenatal multivitamins in the United States. N Engl J Med 360: 939-940.
33. Zimmermann MB, Zeder C, Chaouki N, Torresani T, Saad A et al. (2002) Addition of microencapsulated iron to iodized salt improves the efficacy of iodine in goitrous, iron-deficient children: a randomized, double-blind, controlled trial. Eur J Endocrinol 147: 747-753.

34. Marine D, Kimball OP (1920) Prevention of Simple Goiter in Man. Arch Intern Med 25: 661-672.

35. de Benoist B, Andersson M, Egli I, Takkouche B, Allen H (eds.) (2004) lodine Status Worldwide. In: WHO Global Database on lodine Deficiency. World Health Organization: Geneva.

36. Beaton GH, Martorell R, Aronson KJ, Edmonston B, McCabe G, et al. (1992) Effectiveness of Vitamin A Supplementation in the Control of Young Child Morbidity and Mortality in Developing countries - Nutrition policy discussion paper No. 13. Administrative Committee on Coordination/Sub-Committee on Nutrition: Geneva.

37. Imdad A, Yakoob MY, Sudfeld C, Haider BA, Black RE, et al. (2011) Impact of vitamin A supplementation on infant and childhood mortality. BMC Public Health 11 Suppl 3: S20.

38. Sommer A, Tarwotjo I, Djunaedi E, West KP Jr, Loeden AA, et al. (1986) Impact of vitamin A supplementation on childhood mortality. A randomised controlled community trial. Lancet 1: 1169-1173.

39. Stoltzfus RJ (2001) Iron-deficiency anemia: reexamining the nature and magnitude of the public health problem. Summary: implications for research and programs. J Nutr 131: 697S-700S.

40. Haas JD, Brownlie T 4th (2001) Iron deficiency and reduced work capacity: critical review of the research to determine a causal relationship. J Nutr 131 676S-688S.

41. Pollitt $E$ (2001) The developmental and probabilistic nature of the functiona consequences of iron-deficiency anemia in children. J Nutr 131: 669S-675S.

42. Yip R, Walsh KM, Goldfarb MG, Binkin NJ (1987) Declining prevalence of anemia in childhood in a middle-class setting: a pediatric success story? Pediatrics 80: 330-334.

43. Fomon S (2001) Infant feeding in the 20th century: formula and beikost. J Nut 131: 409S-20S.

44. Layrisse M, Chaves JF, Mendez-Castellano, Bosch V, Tropper E, et al. (1996) Early response to the effect of iron fortification in the Venezuelan population. Am J Clin Nutr 64: 903-907.

45. Stekel A, Olivares M, Cayazzo M, Chadud P, Llaguno S, et al. (1988) Prevention of iron deficiency by milk fortification. II. A field trial with a full-fat acidified milk. Am J Clin Nutr 47: 265-269.

46. Hertrampf E (2002) Iron fortification in the Americas. Nutr Rev 60: S22-25

47. Wimalawansa SJ (2012) Vitamin D: Everything You Need to Know (Nutrition and Vitamin D). Karunaratne \& Sons, Homagama, Sri Lanka.

48. Holick MF (2007) Vitamin D deficiency. N Engl J Med 357: 266-281

49. Gordon CM, DePeter KC, Feldman HA, Grace E, Emans SJ (2004) Prevalence of vitamin $D$ deficiency among healthy adolescents. Arch Pediatr Adolesc Med 158: 531-537.

50. Lips P, Hosking D, Lippuner K, Norquist JM, Wehren L, et al. (2006) The prevalence of vitamin $D$ inadequacy amongst women with osteoporosis: an international epidemiological investigation. J Intern Med 260: 245-254.

51. Mithal A, Wahl DA, Bonjour JP, Burckhardt P, Dawson-Hughes B, et al. (2009) Global vitamin $D$ status and determinants of hypovitaminosis $D$. Osteoporos Int 20: $1807-1820$

52. Chapuy MC, Preziosi P, Maamer M, Arnaud S, Galan P, et al. (1997) Prevalence of vitamin $D$ insufficiency in an adult normal population. Osteoporos Int 7: 439-443.

53. Snijder MB, van Dam RM, Visser M, Deeg DJ, Dekker JM, et al. (2005) Adiposity in relation to vitamin $\mathrm{D}$ status and parathyroid hormone levels: a populationbased study in older men and women. J Clin Endocrinol Metab 90: 4119-4123.

54. van der Wielen RP, Löwik MR, van den Berg H, de Groot LC, Haller J, et al. (1995) Serum vitamin D concentrations among elderly people in Europe. Lancet 346: 207-210.

55. Ovesen L, Andersen R, Jakobsen J (2003) Geographical differences in vitamin D status, with particular reference to European countries. Proc Nutr Soc 62 813-821. 
Citation: Sunil J Wimalawansa (2013) Rational Food Fortification Programs to Alleviate Micronutrient Deficiencies. J Food Process Technol 4: 257. doi:10.4172/2157-7110.1000257

56. Wimalawansa SJ (2012) Vitamin D in the new millennium. Curr Osteoporos Rep 10: 4-15.

57. Wimalawansa SJ (2012) Vitamin D: What clinicians need to know. Sri Lanka Journal of Diabetes, Endocrinology and Metabolism 2: 73-88.

58. Holick MF, Binkley NC, Bischoff-Ferrari HA, Gordon CM, Hanley DA, et al. (2012) Guidelines for preventing and treating vitamin D deficiency and insufficiency revisited. J Clin Endocrinol Metab 97: 1153-1158.

59. Wimalawansa SJ (2011) Vitamin D: an essential component for skeletal health. Ann N Y Acad Sci 1240: E1-12.

60. Allain TJ, Dhesi J (2003) Hypovitaminosis D in older adults. Gerontology 49: 273-278.

61. Bischoff HA, Stähelin HB, Dick W, Akos R, Knecht M, et al. (2003) Effects of vitamin $D$ and calcium supplementation on falls: a randomized controlled trial. J Bone Miner Res 18: 343-351.

62. Calvo MS, Whiting SJ, Barton CN (2004) Vitamin D fortification in the United States and Canada: current status and data needs. Am J Clin Nutr 80: 1710S$6 \mathrm{~S}$.

63. Holick MF, Siris ES, Binkley N, Beard MK, Khan A, et al. (2005) Prevalence of Vitamin D inadequacy among postmenopausal North American women receiving osteoporosis therapy. J Clin Endocrinol Metab 90: 3215-3224.

64. Vieth R (2006) What is the optimal vitamin D status for health? Prog Biophys Mol Biol 92: 26-32.

65. Bosomworth NJ (2011) Mitigating epidemic vitamin D deficiency: the agony of evidence. Can Fam Physician 57: 16-20, e1-6.

66. Goldstein D (2009) The epidemic of vitamin D deficiency. J Pediatr Nurs 24 345-346.

67. Kumar J, Muntner P, Kaskel FJ, Hailpern SM, Melamed ML (2009) Prevalence and associations of 25-hydroxyvitamin D deficiency in US children: NHANES 2001-2004. Pediatrics 124: e362-370.

68. Looker AC, Dawson-Hughes B, Calvo MS, Gunter EW, Sahyoun NR (2002) Serum 25-hydroxyvitamin D status of adolescents and adults in two seasonal subpopulations from NHANES III. Bone 30: 771-777.

69. Rostand SG (1997) Ultraviolet light may contribute to geographic and racial blood pressure differences. Hypertension 30: 150-156.

70. Holick MF, MacLaughlin JA, Doppelt SH (1981) Regulation of cutaneous previtamin D3 photosynthesis in man: skin pigment is not an essential regulator. Science 211: 590-593.

71. Clemens TL, Adams JS, Henderson SL, Holick MF (1982) Increased skin pigment reduces the capacity of skin to synthesise vitamin D3. Lancet 1: 74-76.

72. Matsuoka LY, Wortsman J, Hanifan N, Holick MF (1988) Chronic sunscreen use decreases circulating concentrations of 25 -hydroxyvitamin D. A preliminary study. Arch Dermatol 124: 1802-1804.

73. Welch TR, Bergstrom WH, Tsang RC (2000) Vitamin D-deficient rickets: the reemergence of a once-conquered disease. J Pediatr 137: 143-145.

74. Nesby-O'Dell S, Scanlon KS, Cogswell ME, Gillespie C, Hollis BW, et al. (2002) Hypovitaminosis D prevalence and determinants among African American and white women of reproductive age: third National Health and Nutrition Examination Survey, 1988-1994. Am J Clin Nutr 76: 187-192.

75. Keane EM, Healy M, O'Moore R, Coakley D, Walsh JB (1998) Vitamin D-fortified liquid milk: benefits for the elderly community-based population. Calcif Tissue Int 62: 300-302.

76. Kinyamu HK, Gallagher JC, Rafferty KA, Balhorn KE (1998) Dietary calcium and vitamin $D$ intake in elderly women: effect on serum parathyroid hormone and vitamin D metabolites. Am J Clin Nutr 67: 342-348.

77. Brown KH, Peerson JM, Rivera J, Allen LH (2002) Effect of supplemental zinc on the growth and serum zinc concentrations of prepubertal children: a metaanalysis of randomized controlled trials. Am J Clin Nutr 75: 1062-1071.

78. Bhutta ZA, Black RE, Brown KH, Gardner JM, Gore S, et al. (1999) Prevention of diarrhea and pneumonia by zinc supplementation in children in developing countries: pooled analysis of randomized controlled trials. Zinc Investigators' Collaborative Group. J Pediatr 135: 689-697.
79. Black RE (1998) Therapeutic and preventive effects of zinc on serious childhood infectious diseases in developing countries. Am J Clin Nutr 68: 476S-479S.

80. Nkhoma OW, Duffy ME, Cory-Slechta DA, Davidson PW, McSorley EM, et al. (2013) Early-Stage Primary School Children Attending a School in the Malawian School Feeding Program (SFP) Have Better Reversal Learning and Lean Muscle Mass Growth Than Those Attending a Non-SFP School. J Nutr 143: $1324-1330$

81. Commission CA (1997) Codex Alimentarius Commission. Guidelines for Use of Nutrition and Health Claims CAC/GL 23-1997. J.F.W.S. program.

82. Commission CA (1987) General Principles for the Addition of Essential Nutrients to Foods, CAG/GL09-1987 (amended 1989, 1991). Joint FAO/WHOFood Standards Program, Rome.

83. Food and Agricultural Organization (1996) Food Fortification: Technology and Quality Control (FAO Food and Nutrition Paper - 60). Report of an FAO Technical Meeting held in Rome: Rome, Italy.

84. Spohrer R, Larson M, Maurin C, Laillou A, Capanzana M, et al. (2013) The growing importance of staple foods and condiments used as ingredients in the food industry and implications for large-scale food fortification programs in Southeast Asia. Food \& Nutrition Bulletin 34: S50-S61.

85. Dary O, Imhoff-Kunsch B (2012) Measurement of food consumption to inform food fortification and other nutrition programs: an introduction to methods and their application. Food Nutr Bull 33: S141-S145.

86. WHO (2005) Action on the Social Determinants of Health: Learning from Previous Experiences. World Health Organization, USA.

87. Marmot M, W.R. (1999) Social determinants of health. Oxford University Press, Oxford.

88. Darnton-Hill I, Darnton-Hill I, Nalubola R (2002) Fortification strategies to meet micronutrient needs: successes and failures. Proc Nutr Soc 61: 231-241.

89. Beyer P, Al-Babili S, Ye X, Lucca P, Schaub P, et al. (2002) Golden Rice: introducing the beta-carotene biosynthesis pathway into rice endosperm by genetic engineering to defeat vitamin A deficiency. J Nutr 132: 506S-510S.

90. Ye X, Al-Babili S, Klöti A, Zhang J, Lucca P, et al. (2000) Engineering the provitamin A (beta-carotene) biosynthetic pathway into (carotenoid-free) rice endosperm. Science 287: 303-305

91. Lucca P, Hurrell R, Potrykus I (2002) Fighting iron deficiency anemia with ironrich rice. J Am Coll Nutr 21: 184S-190S

92. WHO (2000) Safety aspects of genetically modified foods of plant origin In: Report of a Joint FAO/WHO Expert Consultation on Foods Derived from Biotechnology, WHO Headquaters: Geneva, Switzerland

93. Solon FS, Klemm RD, Sanchez L, Darnton-Hill I, Craft NE, et al. (2000) Efficacy of a vitamin A-fortified wheat-flour bun on the vitamin A status of Filipino schoolchildren. Am J Clin Nutr 72: 738-744.

94. van Stuijvenberg ME, Dhansay MA, Smuts CM, Lombard CJ, Jogessar VB et al. (2001) Long-term evaluation of a micronutrient-fortified biscuit used for addressing micronutrient deficiencies in primary school children. Public Health Nutr 4: 1201-1209.

95. Latham MC, Ash D, Ndossi G, Mehansho H, Tatala S (2001) Micronutrient dietary supplements--a new fourth approach. Arch Latinoam Nutr 51: 37-41.

96. Abrams SA, Mushi A, Hilmers DC, Griffin IJ, Davila P, et al. (2003) A multinutrient-fortified beverage enhances the nutritional status of children in Botswana. J Nutr 133: 1834-1840.

97. Honein MA, Paulozzi LJ, Mathews TJ, Erickson JD, Wong LY (2001) Impact of folic acid fortification of the US food supply on the occurrence of neural tube defects. JAMA 285: 2981-2986.

98. Jacques PF, Selhub J, Bostom AG, Wilson PW, Rosenberg IH (1999) The effect of folic acid fortification on plasma folate and total homocysteine concentrations. N Engl J Med 340: 1449-1454.

99. Lewis CJ, Crane NT, Wilson DB, Yetley EA (1999) Estimated folate intakes: data updated to reflect food fortification, increased bioavailability, and dietary supplement use. Am J Clin Nutr 70: 198-207. 
Citation: Sunil J Wimalawansa (2013) Rational Food Fortification Programs to Alleviate Micronutrient Deficiencies. J Food Process Technol 4: 257. doi:10.4172/2157-7110.1000257

100.Park YK, Sempos CT, Barton CN, Vanderveen JE, Yetley EA (2000) Effectiveness of food fortification in the United States: the case of pellagra. Am J Public Health 90: 727-738.

101. Ross AC, Manson JE, Abrams SA, Aloia JF, Brannon PM, et al. (2011) The 2011 report on dietary reference intakes for calcium and vitamin $D$ from the Institute of Medicine: what clinicians need to know. J Clin Endocrinol Metab 96: 53-58.

102. Holick MF, Binkley NC, Bischoff-Ferrari HA, Gordon CM, Hanley DA, et al. (2011) Evaluation, treatment, and prevention of vitamin D deficiency: an Endocrine Society clinical practice guideline. J Clin Endocrinol Metab 96 1911-1930.

103. Gideon J (2001) The decentralization of primary health care delivery in Chile. Public Administration and Development 21: 223-231.

104. Hammer J, Gersovitz M (2000) The Economic Control of Infectious Diseases. In: World Bank Policy Research Working Paper No. 2607.
105. Bath PA Sen BA, Raptis DA, Mettler T (2012) Understanding how information and ICTs can improve health. Expert Rev Pharmacoecon Outcomes Res 12 $11-14$.

106. Writing Group (1998) Nutrition and bone health: with particular reference to calcium and vitamin D. Report of the Subgroup on Bone Health, Working Group on the Nutritional Status of the Population of the Committee on Medical Aspects of the Food Nutrition Policy. Rep Health Soc Subj (Lond) 49: iii-xvii, $1-24$

107. Gibson SA (1999) Iron intake and iron status of preschool children: associations with breakfast cereals, vitamin C and meat. Public Health Nutr 2: 521-528.

108. WHO/NHD/01.3 (2001) Iron deficiency anaemia: assessment, prevention and control. In: A guide for programme managers, WHO: Geneva.

109.WHO/NUT/95.3 (1995) Global prevalence of Vitamin A Deficiency. In: Micronutrient Deficiency Information System Working Paper No. 2, WHO: Geneva. 